\title{
Gibberellin 20-Oxidase Gene OsGA20ox3 Regulates Plant Stature and Disease Development in Rice
}

\author{
Xue Qin, ${ }^{1,2}$ Jun Hua Liu, ${ }^{1,2}$ Wen Sheng Zhao, ${ }^{1,2}$ Xu Jun Chen, ${ }^{2}$ Ze Jian Guo, ${ }^{2}$ and You Liang Peng ${ }^{1,2}$ \\ ${ }^{1}$ State Key Laboratory of Agrobiotechnology and ${ }^{2}$ Department of Plant Pathology, China Agricultural University, \\ Yuanmingyuan West Road 2, Beijing 100193, China
}

Submitted 29 May 2012. Accepted 12 September 2012.

Gibberellin (GA) 20-oxidase (GA20ox) catalyses consecutive steps of oxidation in the late part of the GA biosynthetic pathway. A T-DNA insertion mutant (17S-14) in rice, with an elongated phenotype, was isolated. Analysis of the flanking sequences of the T-DNA insertion site revealed that an incomplete T-DNA integration resulted in enhanced constitutively expression of downstream OsGA20ox3 in the mutant. The accumulation of bioactive $\mathrm{GA}_{1}$ and $\mathrm{GA}_{4}$ were increased in the mutant in comparison with the wild-type plant. Transgenic plants overexpressing OsGA20ox3 showed phenotypes similar to those of the $17 \mathrm{~S}-14$ mutant, and the RNA interference (RNAi) lines that had decreased OsGA20ox3 expression exhibited a semidwarf phenotype. Expression of $O s G A 20 o x 3$ was detected in the leaves and roots of young seedlings, immature panicles, anthers, and pollens, based on $\beta$-glucuronidase (GUS) activity staining in transgenic plants expressing the OsGA20ox3 promoter fused to the GUS gene. The OsGA20ox3 RNAi lines showed enhanced resistance against rice pathogens Magnaporthe oryzae (causing rice blast) and Xanthomonas oryzae pv. oryzae (causing bacterial blight) and increased expression of defense-related genes. Conversely, OsGA20ox3-overexpressing plants were more susceptible to these pathogens comparing with the wild-type plants. The susceptibility of wild-type plants to $X$. oryzae pv. oryzae was increased by exogenous application of $\mathrm{GA}_{3}$ and decreased by S-3307 treatment. Together, the results provide direct evidence for a critical role of OsGA200x3 in regulating not only plant stature but also disease resistance in rice.

Gibberellins (GA) are a group of tetracyclic diterpenoid compounds, some of which play important roles in regulating many aspects of plant growth and development, such as seed germination, stem elongation, leaf expansion, and flower and fruit development (MacMillan 2002; Silverstone and Sun 2000). Genetic and biochemical studies have revealed many genes that participate in GA biosynthesis or signal transduction pathways (Hedden and Phillips 2000; Hedden et al. 2002; Kaneko et al. 2003; Sakamoto et al. 2004). GA are

\section{Qin and J.-H. Liu contributed equally to the work.}

Corresponding authors: Z. J. Guo; Telephone and Fax: +86-10-62734962; E-mail: guozj@cau.edu.cn; and Y.-L. Peng; E-mail: pengyl@cau.edu.cn

* The $\boldsymbol{e}$-Xtra logo stands for "electronic extra" and indicates that one supplementary table is published online. Also, Figures 1, 4, and 5 appear in color online.

(C) 2013 The American Phytopathological Society synthesized from trans-geranylgeranyl diphosphate (GGDP), which is a universal precursor for diterpenoids. ent-Kaurene is produced by sequential cyclizations of GGDP via two kinds of diterpene cyclases in proplastid, ent-copalyl diphosphate synthase (CPS) and ent-kaurene synthase (KS). entKaurene is then converted to $\mathrm{GA}_{12}$ via two steps of oxidations by cytochrome P450 monooxygenases, ent-kaurene oxidase (KO) and ent-kaurenoic acid oxidase (KAO), in the endoplasmic reticulum membrane. Bioactive $\mathrm{GA}_{1}$ and $\mathrm{GA}_{4}$ are synthesized from $\mathrm{GA}_{12}$ through two parallel pathways (i.e., early-13-hydroxylation and non-13-hydroxylation pathways) by two kinds of 2-oxoglutarate-dependent dioxygenases in the cytoplasm, GA 20-oxidases (GA20ox) and GA 3-oxidases (GA3ox). GA20ox catalyzes the sequential oxidation of C-20 from a methyl group to its removal as $\mathrm{CO}_{2}$, producing $\mathrm{C}_{19}$-GA $\left(\mathrm{GA}_{9}\right.$ and $\left.\mathrm{GA}_{20}\right)$. Subsequently, the introduction of a $\beta$-hydroxyl group by GA3ox converts the inactive $\mathrm{C}_{19^{-}}$ GA precursors to bioactive GA (Hedden and Phillips 2000; Olszewski et al. 2002).

The enzymes catalyzing early steps in GA biosynthetic pathway, such as CPS, KS, and KO, are generally encoded by one or two genes. For example, there are four $C P S$ genes identified in the rice genome, including a pseudogene, OSCPS3. However, only OsCPS1 is shown to be involved in GA biosynthesis (Sakamoto et al. 2004). OsCPS2 and OsCPS4 participate in the biosynthesis of phytoalexins (Otomo et al. 2004; Prisic et al. 2004; Sakamoto et al. 2004). A loss-of-function mutation in OsCPS1 causes serious dwarfism. The enzymes catalyzing later steps in the GA biosynthetic pathway, such as GA20ox and GA3ox, are encoded by small gene families. The semidwarf 1 ( $s d l$ ) mutant, known to be mutated in the "Green Revolution Gene", shows a semidwarfism phenotype with strong lodging resistance and increased yields compared with the wild-type (WT) progenitor (Wolfgang et al. 2002). The SDI encodes an OsGA20ox2 gene located on chromosome 1 in rice. RNA interference (RNAi)-mediated suppression of OsGA20ox2 transcript also causes a semidwarf phenotype in rice, similar to the phenotype of $s d l$ (Qiao et al. 2007). There are four OsGA20ox-like genes in the rice genome and they differ in their expression patterns (Sakamoto et al. 2004), suggesting that they may play different roles. The OsGA20oxl gene has been characterized based on its overexpression, which causes a tall and GA-overproduction phenotype (Oikawa et al. 2004). RNAi-mediated suppression of OsGA20oxl expression results in phenotypes that are similar to those of $s d l$, indicating that OsGA20ox1 and OsGA20ox2 probably have complementary function in GA synthesis and regulation of plant stature (Oikawa et al. 2004). In Arabidopsis, AtGA20oxl and AtGA20ox2, two of the five known GA20ox genes, act partially redundantly to promote growth and development (Rieu et al. 2008). 
Plant height is one of the most important traits in crop breeding because of its relevance to lodging resistance. A number of dwarf or tall mutants of rice have been isolated, and some of them have been characterized as enzymes involved in GA biosynthesis or components in GA signaling pathways. The GA receptor mutant gibberellin-insensitive dwarfl (gidl) shows serious dwarfism and the mutant phenotype cannot be restored by application of exogenous GA. The WT GID1 receptor protein directly binds to active GA and, subsequently, interacts with DELLA transcriptional repressors. The GA-GID1-bound DELLA proteins are recognized and ubiquinated by an E3 ubiquitin ligase (Skp1, Cullin, and F-box $[\mathrm{SCF}]^{\mathrm{GID} 2 / \mathrm{SLY} 1}$ ), leading to degradation of DELLA proteins through the proteasome pathway (Ueguchi-Tanaka et al. 2005, 2007). Degradation of DELLA repressors activates GA action. Arabidopsis contains multiple DELLA proteins, whereas rice has only one, called SLENDER RICE1 (SLR1). The slr1 mutant exhibits constitutive GA signaling and responses (Ikeda et al. 2001).

Although GA are widely recognized as phytohormones that play important roles in plant growth and development, emerging evidence implicates GA in the processes of pathogen infection. In fact, GA was originally identified from the necrotrophic fungus Gibberella fujikuroi (Fusarium moniliforme), which causes the bakanae or foolish-seedling disease of rice (Yabuta and Sumiki 1938). Among many symptoms, the infected plants are slender, caused by excessive growth of the stem, and often are incapable of supporting their own weight, topple over, and die (hence "foolish seedling disease"). The mutant elongated uppermost internode (eui), with increased accumulation of active GA (Zhu et al. 2006), has compromised disease resistance to Xanthomonas oryzae pv. oryzae and Magnaporthe oryzae (Yang et al. 2008). The gidl mutant, which exhibited typical GA-deficient phenotypes despite elevated GA contents, shows increased tolerance to cold stress as well as resistance to rice blast fungus $M$. oryzae (Tanaka et al. 2006). Interestingly, the OsCPS1 transcript is downregulated, whereas expression of $O s C P S 2$ and $O s C P S 4$ in the phytoalexin biosynthesis pathway is upregulated in gidl (Tanaka et al. 2006). These results suggest that GA homeostasis participates in responses to pathogen attack.

In this report, we isolated a T-DNA insertion mutant (17S-14) in rice which showed a tall and elongated phenotype. Further analysis revealed an irregular T-DNA integration that resulted in a Cauliflower mosaic virus (CaMV) 35S promoter located upstream of the OsGA20ox3 gene in the mutant. Transgenic overexpression and knockdown of OsGA20ox3 expression showed elongated and semidwarf phenotypes, respectively, and exhibited altered resistance to pathogen infections. Our results provide direct evidence for a critical dual role of OsGA20ox3 in regulating plant stature and disease resistance in rice.

\section{RESULTS}

\section{Characterization of rice T-DNA insertion mutant 17S-14 with GA overproduction phenotypes.}

In a project to examine the role of the wall-associated kinase 2 (OsWAK2) gene in disease resistance, the full-length coding sequence of $O s W A K 2$ was isolated and inserted into a modified pCambia1301 vector under the control of a CaMV35S promoter (Li et al. 2009). The OsWAK2 overexpression construct was used to transform rice 'Aichi Asahi'. One transformant, $17 \mathrm{~S}-14$, differed in appearance from all other transgenic lines harboring the CaMV35S:OsWAK2 construct. Genetic analysis showed that the $T_{1}$ plants yielded a segregation of 17 tall plants with resistance to hygromycin (Hyg) and 6 Hygsensitive plants of normal height, indicating dominant inheri- tance of the elongated phenotype. Line $17 \mathrm{~S}-14$ was approximately $55 \pm 4 \mathrm{~cm}$ taller than WT parents $(104 \pm 3 \mathrm{~cm})$ under the natural long-day conditions in Beijing, China. The mature plants of line 17S-14 have a taller stature, longer spikes, longer internodes, and more elongated internodes than WT plants (Fig. 1B and C). Seed of line 17S-14 germinated earlier and seedlings grew faster than its WT parents (Fig. 1A and B). These characteristics were similar to those of rice plants treated with active GA or a GA-overproduction mutant such as B142 (Oikawa et al. 2004), suggesting that 17S-14 is a GAoverproduction or hyper-responsive mutant.

We investigated the responses of the $17 \mathrm{~S}-14$ mutant to $\mathrm{GA}_{3}$, an active GA, and S-3307, a GA biosynthesis inhibitor (similar to uniconazole). Germinated seed of the WT and the $17 \mathrm{~S}-14$ mutant were transferred to one-half Murashige-Skoog medium containing various levels of $\mathrm{GA}_{3}$ or S-3307 for growth. The growth of $17 \mathrm{~S}-14$ seedlings was enhanced by treatment with $\mathrm{GA}_{3}$, similar to the response of the WT plants applied with $\mathrm{GA}_{3}$ (Fig. 2A and C). In addition, inhibition of growth was observed in both of the $17 \mathrm{~S}-14$ mutant and WT plants treated with $5 \mu \mathrm{M} \mathrm{S}-3307$ (Fig. 2A and B). Normal responses of the 17S-14 mutant to GA and GA biosynthesis inhibitor suggest that the GA signal-transduction pathway is maintained intact.

\section{Isolation of the flanking sequences}

of the T-DNA insertion site from the 17S-14 mutant.

Southern blot analysis revealed a single T-DNA insertion in the 17S-14 line using the Hyg phosphotransferase gene as a hybridization probe (Fig. 3A), suggesting that the mutant phenotype may be caused by the T-DNA insertion. However, we were unsuccessful in using the thermal asymmetrical interlaced polymerase chain reaction (PCR) method to isolate the flanking sequences at the T-DNA insertion site in the 17S-14 mutant (Liu et al. 1995). Next, we constructed a genomic library of the $17 \mathrm{~S}-14$ mutant and screened it using the Hyg gene as a probe. The flanking sequences were obtained by sequencing six positive clones and found to correspond to the sequence of the BAC clone OsJNBa0050F10 (accession number AP005840) from chromosome 7. The site of T-DNA insertion is located $385 \mathrm{bp}$ upstream of a possible translation start site of the OsGA20ox3 gene (Fig. 3B). Sequence analysis revealed that the T-DNA insert in the $17 \mathrm{~S}-14$ genome was incomplete, containing a deletion from the middle of the OsWAK2 transgene to the left border of TDNA (Fig. 3C). The deletion resulted in loss of not only the $3^{\prime}$ half of the $O s W A K 2$ gene but also the $\beta$-glucuronidase $(G U S)$ reporter gene in the T-DNA vector, agreeing with the result of undetectable band using the $G U S$ gene as probe in the Southern blot analysis (Fig. 3A).

\section{Increased expression of the $O s G A 20 o x 3$ gene and accumulation of active $\mathrm{GA}$ in the $17 \mathrm{~S}-14$ mutant.}

The GA20ox is a key enzyme of the later steps of the GA biosynthesis pathway. Four GA20ox-like genes exist in the rice genome (Sakamoto et al. 2004). The deduced amino acid sequence of OsGA20ox3 contains the conserved amino acid sequences of NHYPPCRQP for binding the 2-oxoglutarate substrate, three histidine (His) residues for binding $\mathrm{Fe}^{2+}$, and the amino acid sequence LPWKET for binding GA substrates (Sakamoto et al. 2004). Because two CaMV35S promoters were located very close to OsGA20ox3 gene, we speculated that the transcription of OsGA20ox3 might be enhanced in mutant $17 \mathrm{~S}-14$ plants, resulting in increased GA biosynthesis. Indeed, by reverse-transcriptase (RT)-PCR analysis, we detected an elevated level of OsGA20ox3 transcript in the 17S-14 mutant compared with that of WT plants (Fig. 3D). Next, we conducted quantitative analysis of endogenous GA by using a liquid chromatography mass spectrometry (LC-MS) method. 
A

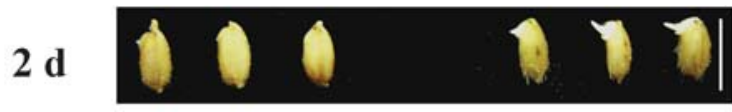

$4 \mathrm{~d}$

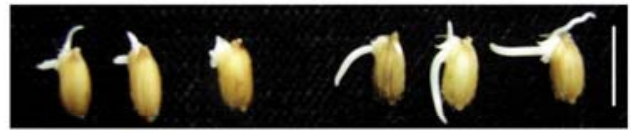

7 d

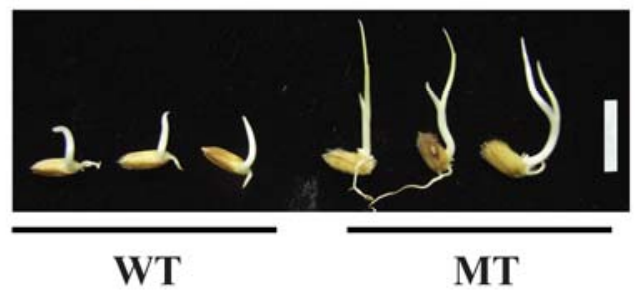

B
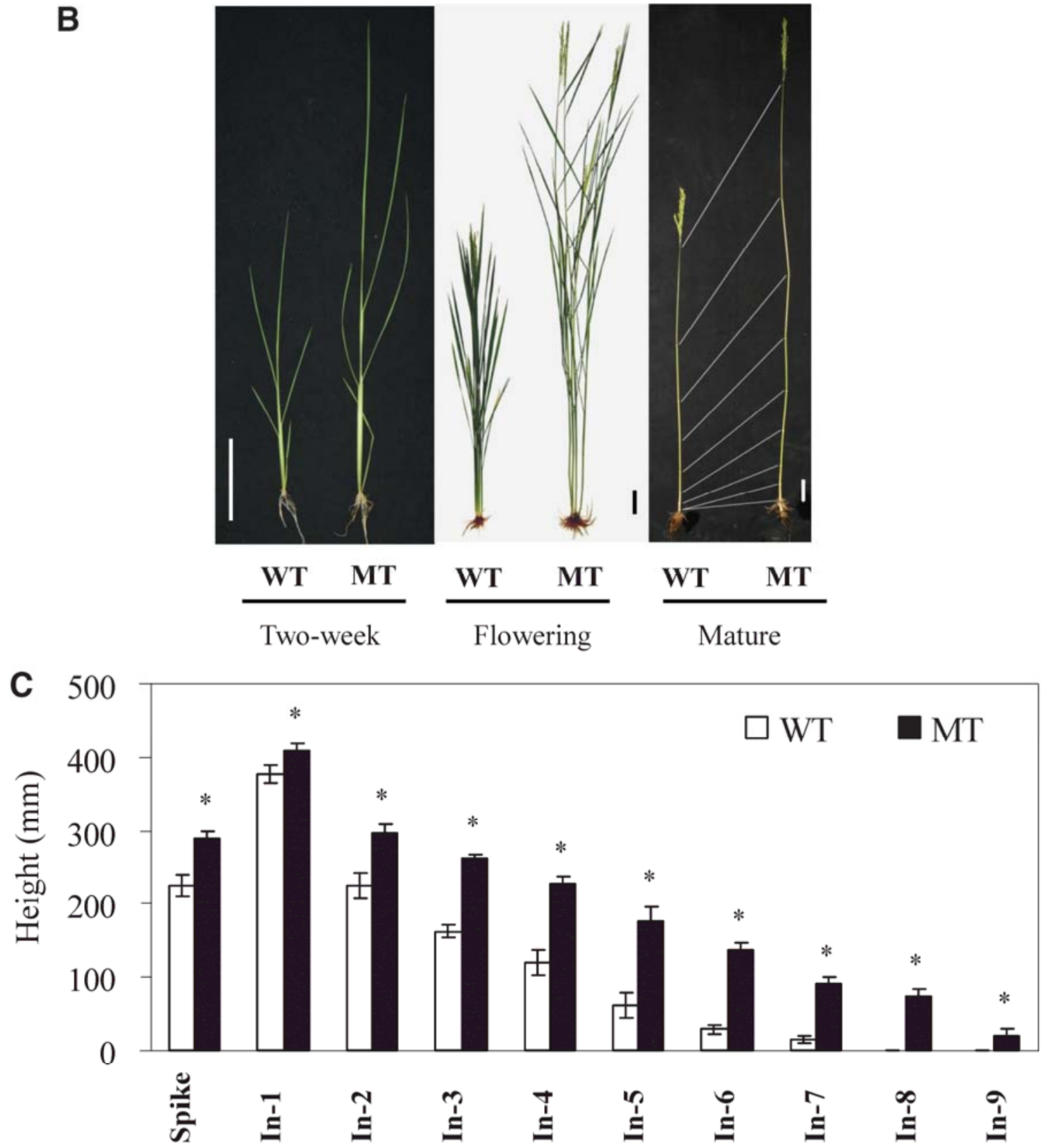

Fig. 1. Characteristics of the 17S-14 plant. A, Seed germination of wild-type (WT) and the 17S-14 mutant (MT). B, Statures of the WT and MT at 2-weekold (left), flowering (middle), and mature (right) stages. C, Lengths of spikes and internodes (In-1 to In-9) of WT and MT were measured from six plants. Error bars indicate standard errors of the mean. Bars $=1 \mathrm{~cm}(\mathrm{~A})$ and $10 \mathrm{~cm}(\mathrm{~B})$. Asterisk indicates significant differences between the control and the overexpressing lines (* indicates $P<0.05$, Fieldman Rank Sums test). 
The active GA molecules of $\mathrm{GA}_{1}$ and $\mathrm{GA}_{4}$ accumulated higher in 17S-14 plants compared with the WT plants (Table 1). Taken together, these results indicated that increased GA accumulation is likely a cause of the excessive shoot elongation in the $17 \mathrm{~S}-14$ mutant plant.

\section{Developmental regulation of the $O s G A 20 o x 3$ gene.}

To examine the expression of OsGA20ox3 in different organs, RT-PCR analysis of the OsGA20ox3 transcript was performed using total RNA isolated from various organs of the WT and $17 \mathrm{~S}-14$ plants. OsGA20ox3 was broadly expressed in vegeta- tive organs of 2-week-old seedlings, including leaves, sheaths, and roots (Fig. 4A). The OsGA20ox3 transcript was most abundant in the panicles and not detected in leaves, sheaths, culms, or roots at the heading stage of rice. In contrast, the OsGA20ox3 transcript accumulated at high levels in all organs examined in the $17 \mathrm{~S}-14$ plants (Fig. 4A).

To further investigate the expressing patterns of OsGA20ox3 in detail, we fused the OsGA20ox3 promoter with the GUS gene $\left(\mathrm{P}_{\text {OsGA20ox } 3}: G U S\right)$ and transformed it into Aichi Asahi rice plants. A representative GUS activity pattern is shown in Figure 4B. GUS activity was detected in transgenic callus, germi-
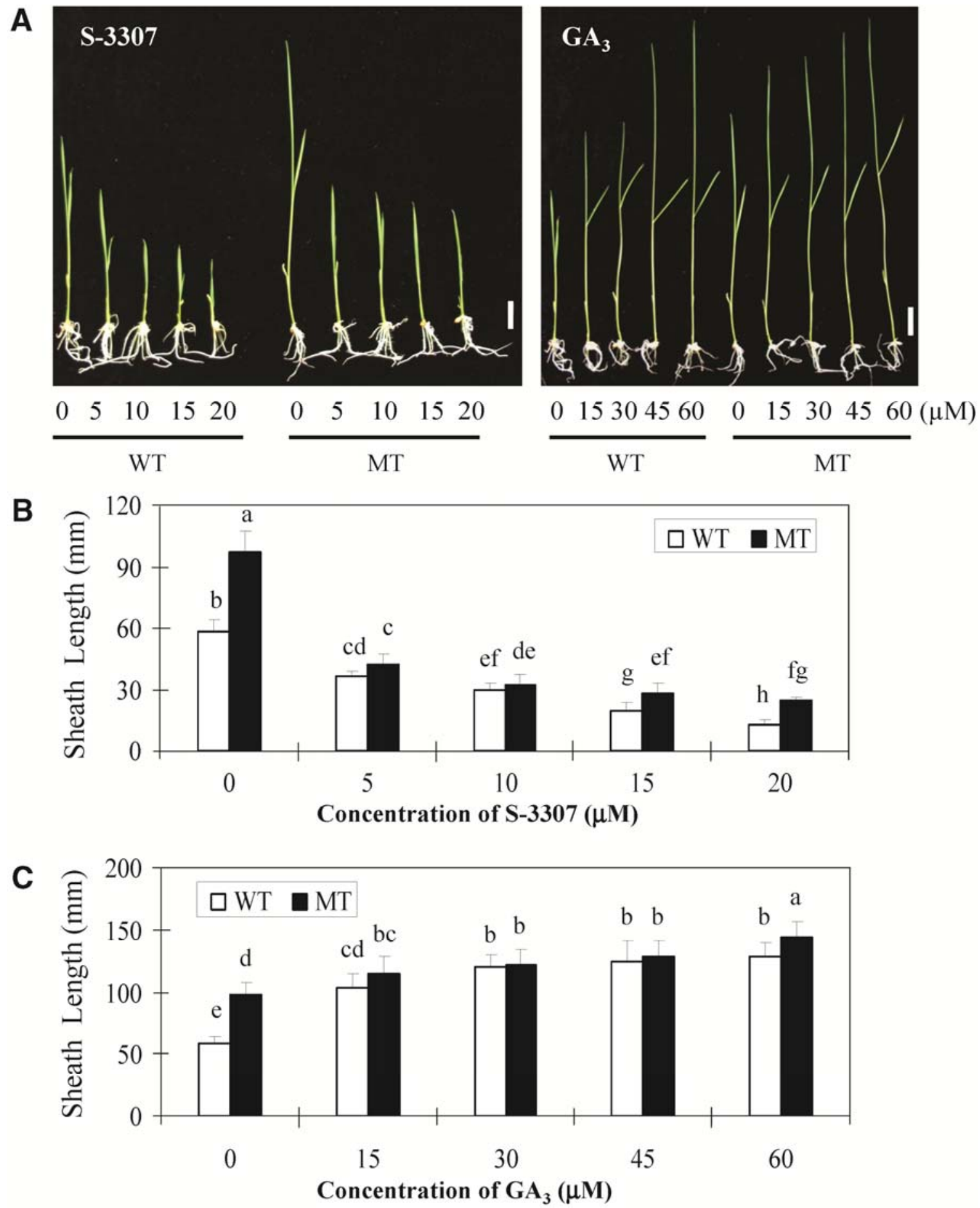

Fig. 2. Effect of $\mathrm{GA}_{3}$ or S-3307 treatment on seedling growth. A, Seedlings of wild-type (WT) and the $17 \mathrm{~S}-14$ mutant (MT) were cultured on one-half Murashige-Skoog solid medium (1\% agar) containing different concentrations of S-3307 or GA 3 for 10 days. The second leaf sheath lengths were measures and the mean values from six plants were shown for $\mathbf{B}, \mathrm{S}-3307$ and $\mathbf{C}, \mathrm{GA}_{3}$ treatments. Error bars indicate standard errors of the mean. Bar $=2 \mathrm{~cm}$. 
nating seed, and sheaths and roots of seedlings (Fig. 4Ba to c). Furthermore, GUS activity was found in young panicles, anthers, and pollens (Fig. 4Bd to j) but not in leaves, sheaths, roots, or culms at the heading stage (data not shown). Therefore, the results obtained by GUS staining were in agreement with the expressing patterns revealed by RT-PCR analysis.
The $O s G A 20 o x 3$ gene plays a positive role in plant stature.

To investigate the biological functions of OsGA20ox3, the coding region of $O s G A 20$ ox 3 driven by the CaMV35S promoter (CaMV35S:OsGA20ox3) was introduced into rice (Aichi Asahi). In addition, an RNAi construct was transformed into rice. Of 21 transformants harboring the CaMV35S:OsGA20ox 3
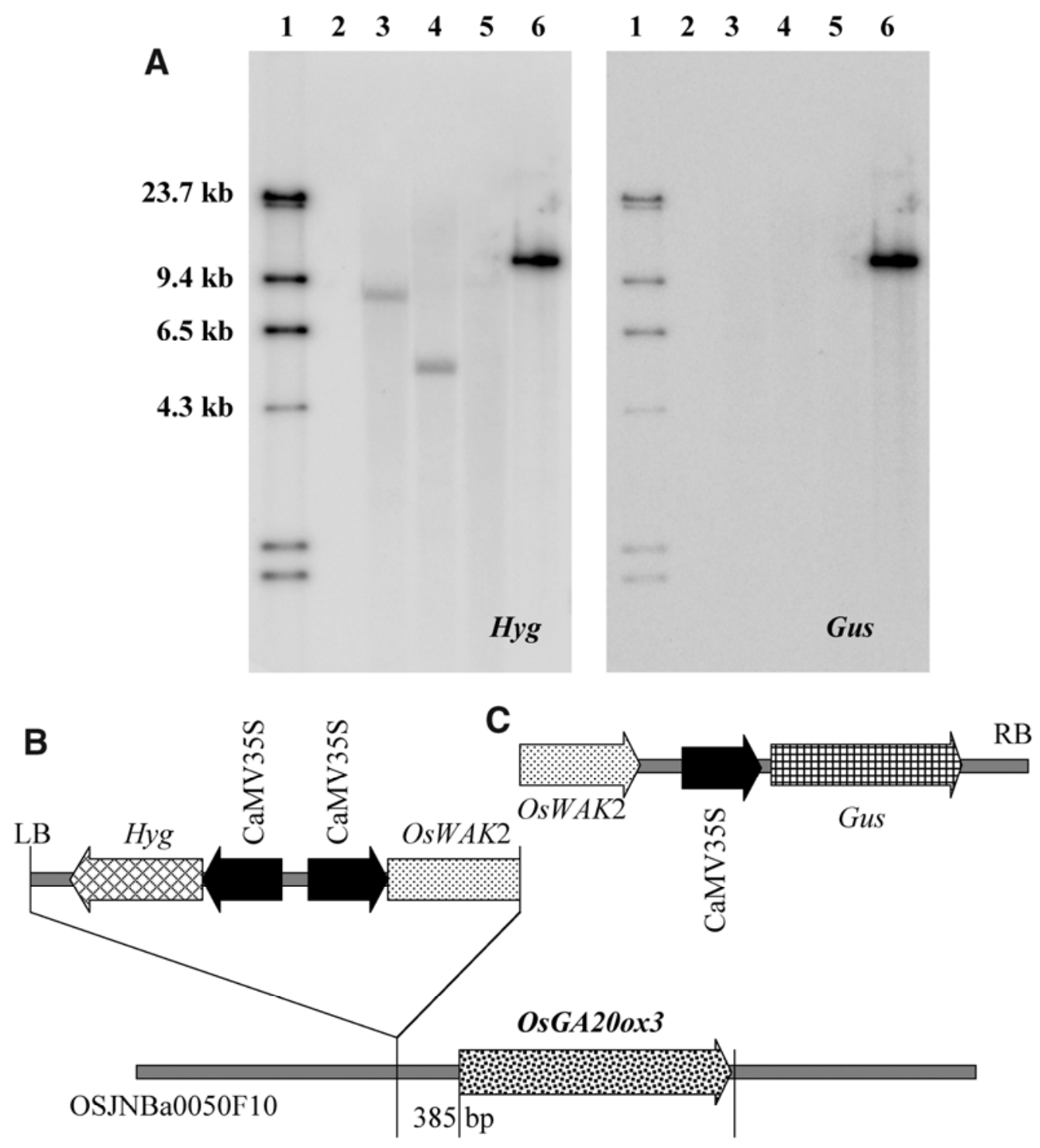

78409

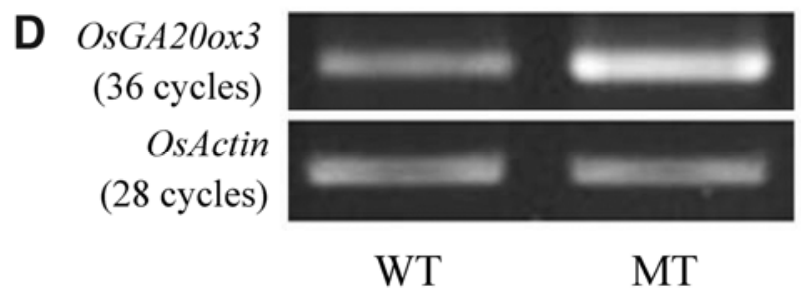

Fig. 3. Characterization of the T-DNA insertion in line 17S-14. A, Southern blot analysis using the genomic DNA (20 $\mu$ g per each lane) from wild-type (WT) and the 17S-14 mutant (MT) plants. From lane 3 to 5, the DNA from MT was digested with HindIII, EcoRI, and ApaI, respectively. The DNA from WT (lane 2) and the pCambia1301 vector (lane 6) digested with HindIII were used as the negative and positive controls, respectively. HindIII-fragmented $\lambda$ DNA was used as the size markers (lane 1). Fragments of hygromycin (Hyg) (left) or $\beta$-glucuronidase (GUS) (right) were labeled with ${ }^{32} \mathrm{P}$ and used as hybridization probes. B, Diagram of the T-DNA insertion site in the 17S-14 plant. The T-DNA was located in the BAC clone OSJNBa0050F10 (contains $151,986 \mathrm{bp}$ ) at the position of 78,409 bp and located at $385 \mathrm{bp}$ upstream of the potential translation start site of OsGA20ox3. C, Diagram shown the part of the original $O s W A K 2$ transgene construct missing in the $17 \mathrm{~S}-14$ plant. D, Expression of OsGA20ox3 was analyzed by the reverse-transcriptase polymerase chain reaction (PCR) method using the total RNA isolated from 2-week-old seedlings. The PCR products were separated by electrophoresis in a $1.2 \%$ (wt/vol) agarose gel and the DNA bands were visualized using an Alphaimager 2200 system. The experiments were repeated 10 times and similar results were obtained. The OsActin gene was used as an internal standard. 
construct, 18 showed tall, elongated internode phenotypes, similar to that of 17S-14 mutant plants (Fig. 5A). Of 15 RNAi lines, 3 showed semidwarf phenotypes (Fig. 5A). Transcription analyses revealed that $O s G A 200 x 3$ expression was enhanced in the overexpressing lines OV4 and OV5, which showed elongated seedling phenotypes. In contrast, OsGA20ox3 expression was significantly suppressed in the RNAi lines RI9 and RI11, which show a semidwarf phenotype, compared with the WT and the RNAi lines RI8 and RI10 plants, which exhibited a relatively

Table 1. Endogenous concentration of gibberellin $(\mathrm{GA})_{1}$ and $\mathrm{GA}_{4}$ in wildtype and $17 \mathrm{~S}-14$ mutant seedlings ${ }^{\mathrm{a}}$

\begin{tabular}{lcr}
\hline & \multicolumn{2}{c}{ Concentration $\left(\mathbf{n g ~ g}^{-\mathbf{1}}\right.$ fresh weight $)$} \\
\cline { 2 - 3 } & $\mathbf{G A}_{\mathbf{1}}$ & $\mathbf{G A}_{\mathbf{4}}$ \\
\hline Wild-type & $0.07 \pm 0.02$ & $1.73 \pm 0.08$ \\
17S-14 mutant & $6.70 \pm 1.31$ & $20.49 \pm 0.51$ \\
\hline
\end{tabular}

${ }^{a}$ GA were extracted from entire seedlings of the $17 \mathrm{~S}-14$ mutant and its progenitor with two biological replicates and analyzed by liquid chromatography mass spectrometry. normal growth phenotype (Fig. 5B and C). In addition, we examined the effects of OsGA20ox3 RNAi and overexpression on the expression of its close homologs. We found that the expression of OsGA20ox3 homologs was not markedly different in the $O s G A 200 x 3$-overexpressing plants compared with that in the WT plants, except that OsGA20ox2 was modestly elevated (approximately twofold) in line $17 \mathrm{~S}-14$ and, to a lesser extent, also in some of the OsGA20ox 2 overexpression lines. In contrast, alteration of gene expression was highly specific for OsGA20ox3 in the RNAi lines of semidwarves, without significant effect on the level of homologous OsGA20ox1, OsGA20ox2, and OsGA20ox4 (Fig. 5D). The results provide the first evidence that OsGA20ox3 plays a positive role in plant stature of rice and suggest that OsGA20ox3 overexpression is likely the reason for the elongated phenotype of $17 \mathrm{~S}-14$ mutant plants.

\section{Increase $O s G A 20 o x 3$ expression enhances rice susceptibility to pathogens.}

Accumulating data showed that GA is also involved in disease responses in rice (Tanaka et al. 2006; Yang et al. 2008).

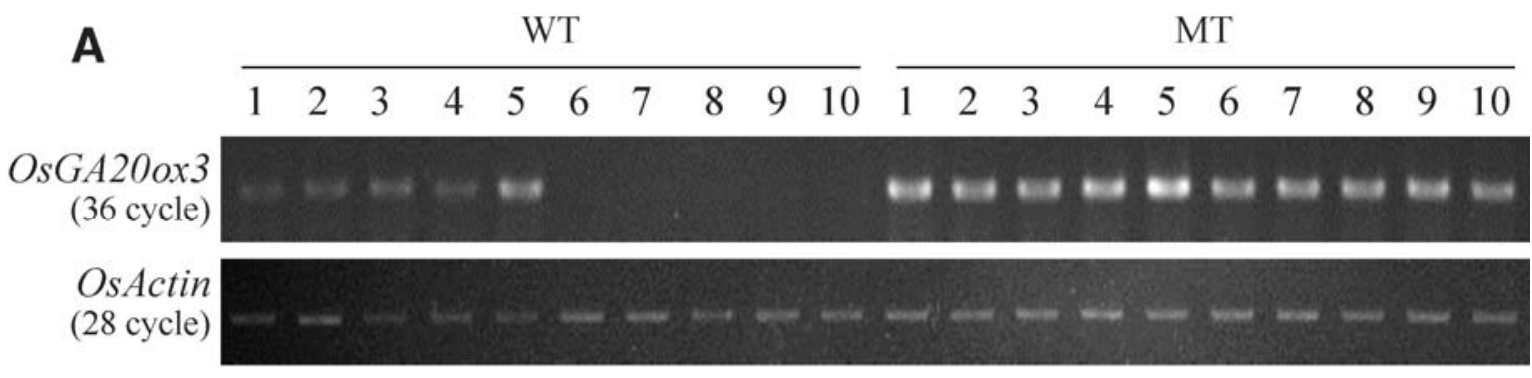

B
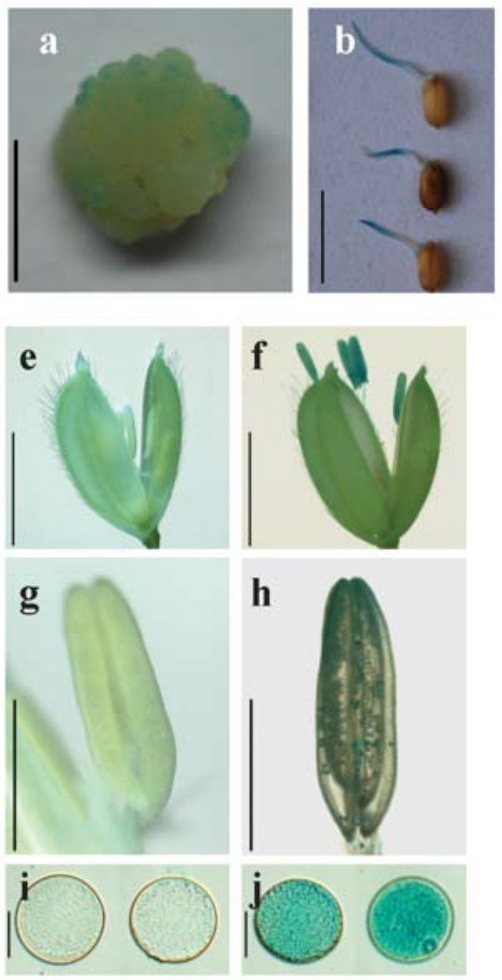

h
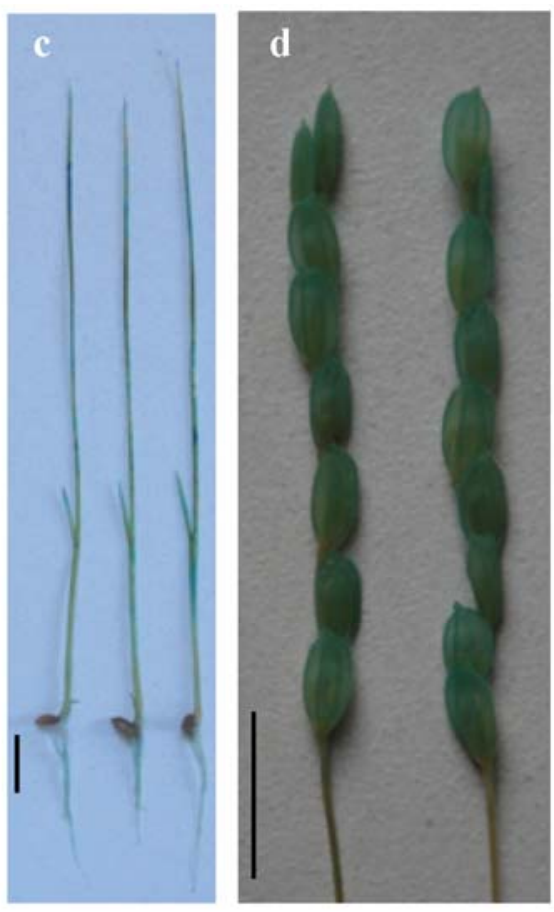

WT

Transformants

Fig. 4. Developmental expression patterns of OsGA20ox3. A, Expression patterns of OsGA20ox3 in wild-type (WT) and 17S-14 mutant (MT) plants were examined by reverse-transcriptase polymerase chain reaction. Total RNAs were extracted from various tissues of 2-week-old seedlings (lanes 1 to 4: leaves, upper part of sheaths, lower part of sheaths, and roots, respectively) and at the heading stage (lanes 5 to 10: panicles, leaves, sheaths, upper part of culms, lower part of culms, and roots, respectively). OsActin gene was used as an internal standard. B, a, Histochemical $\beta$-glucuronidase (GUS) staining of $\mathrm{P}_{\text {OSGA20ox } 3}$ :GUS transgenic calli. GUS activity in $\mathbf{b}, 3$-day-old and $\mathbf{c}, 10$-day-old seedlings; $\mathbf{d}$, young and $\mathbf{f}$, flowering panicles; $\mathbf{h}$, anthers; and $\mathbf{j}$, pollens. e, $\mathbf{g}$, and $\mathbf{i}$, GUS staining of WT plants used as the corresponding controls. Bars $=1 \mathrm{~cm}$ (a to f), $0.1 \mathrm{~cm}(\mathrm{~g}$ and $\mathrm{h}$ ), and $20 \mu \mathrm{m}$ ( $\mathrm{i}$ and $\mathrm{j}$ ). 
Therefore, we investigated whether OsGA20ox3 plays a role in responses to pathogen infection of rice. Transgenic plant overexpressing or underexpressing OsGA20ox3, 17S-14 mutant, and their corresponding WT plants were inoculated with rice blast fungal strain MS220. The 17S-14 mutant exhibited more severe disease symptoms, including larger lesions, than the WT plants (Fig. 6A and B). Similarly, OsGA20ox3-overexpressing lines OV4 and OV5 were more susceptible to the rice blast

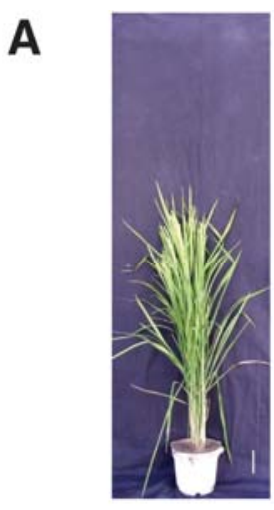

WT

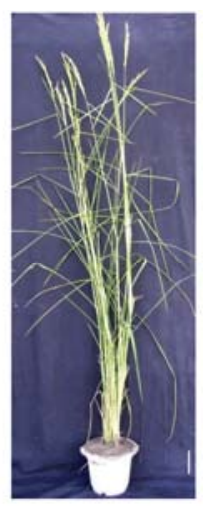

MT

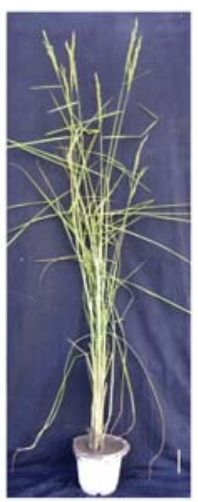

OV4

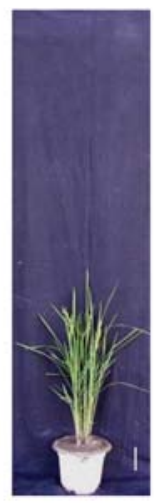

RI11

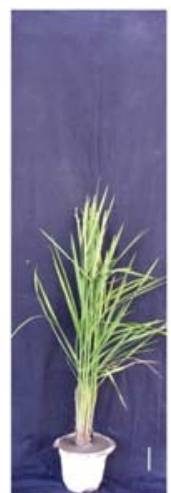

RI16

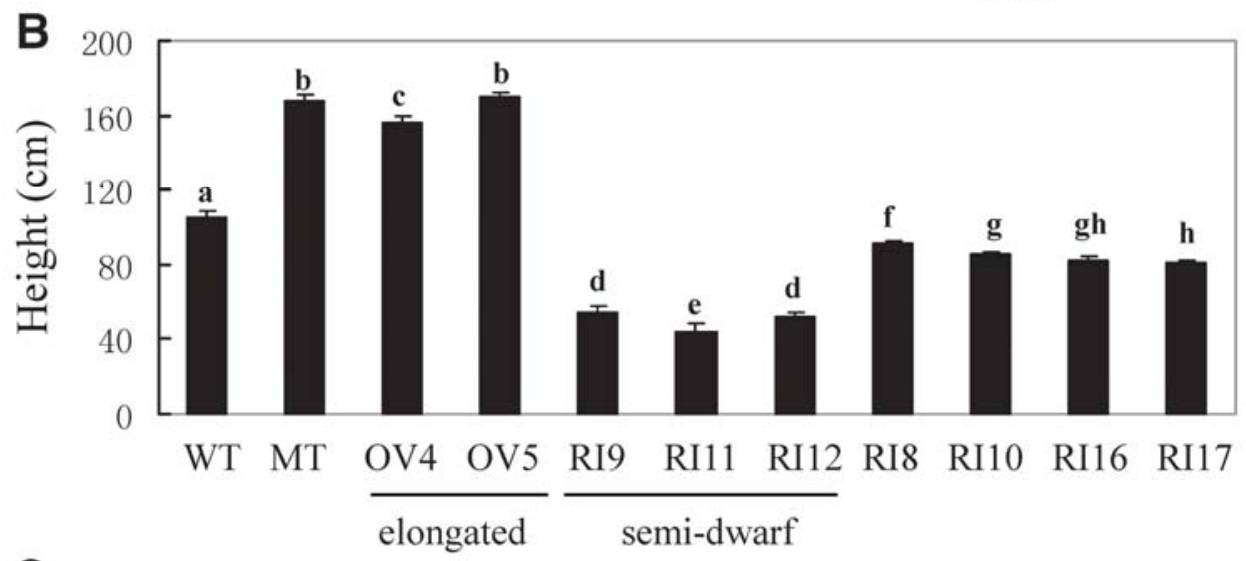

C
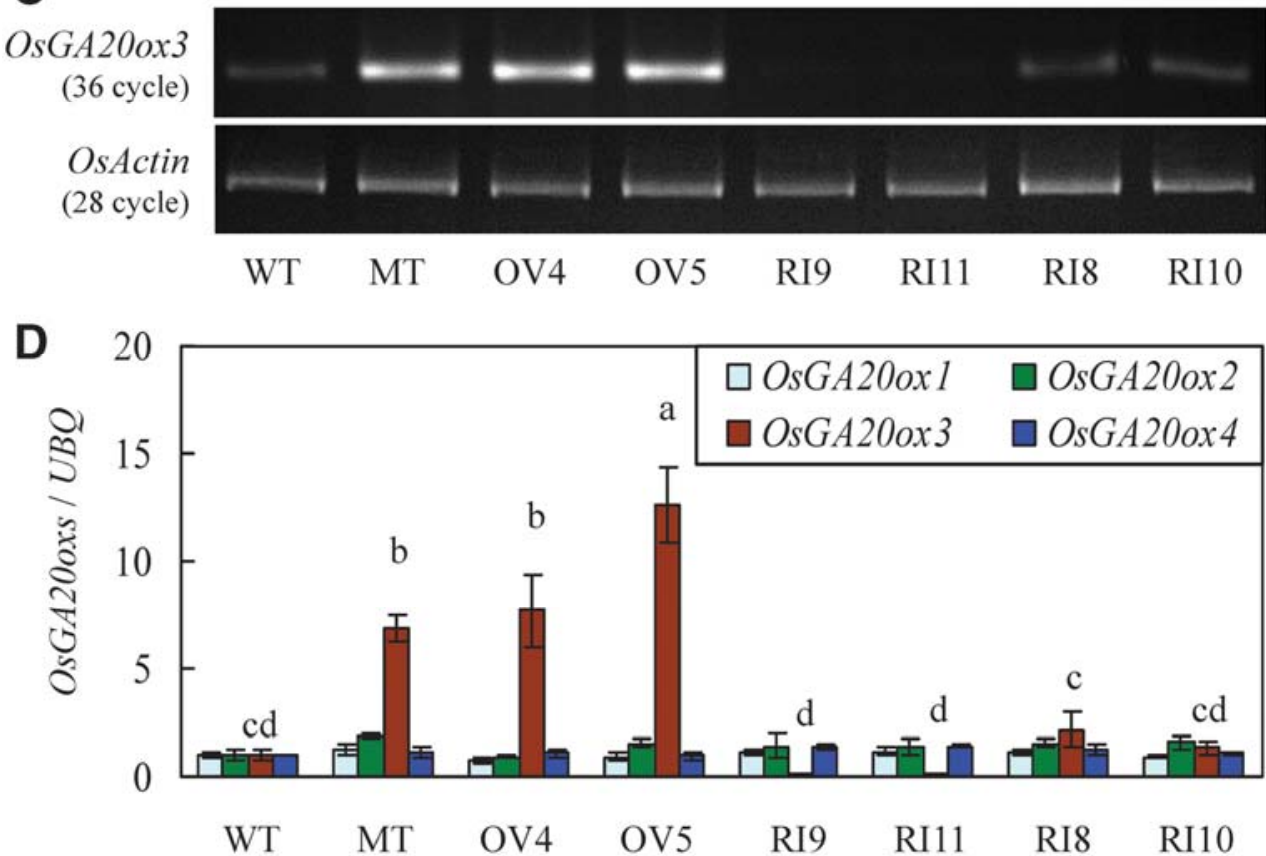

Fig. 5. Characterization of OsGA20ox3 overexpression and RNA interference (RNAi) plants. A, Comparison of the statures of OsGA20ox3 overexpression (OV4) and RNAi (RI11 and RI6) lines $\left(\mathrm{T}_{1}\right)$ with wild-type (WT) and 17-14S mutant (MT) plants. B, Plant heights and standard errors of six plants are shown. Analysis of gene expression was performed by $\mathbf{C}$, reverse-transcriptase polymerase chain reaction (RT-PCR) and D, quantitative PCR (qPCR) using 2-week-old seedlings of WT, MT, and overexpressing (OV4 and OV5) and RNAi (RI8-RI11) lines at the $\mathrm{T}_{2}$ generation. Actin (OsActin) and ubiquitin (UBQ) genes were used as internal standards for RT-PCR and qPCR, respectively. Mean values from three repeats are shown. Error bars indicate standard errors of the mean. Bar $=10 \mathrm{~cm}$. 
A

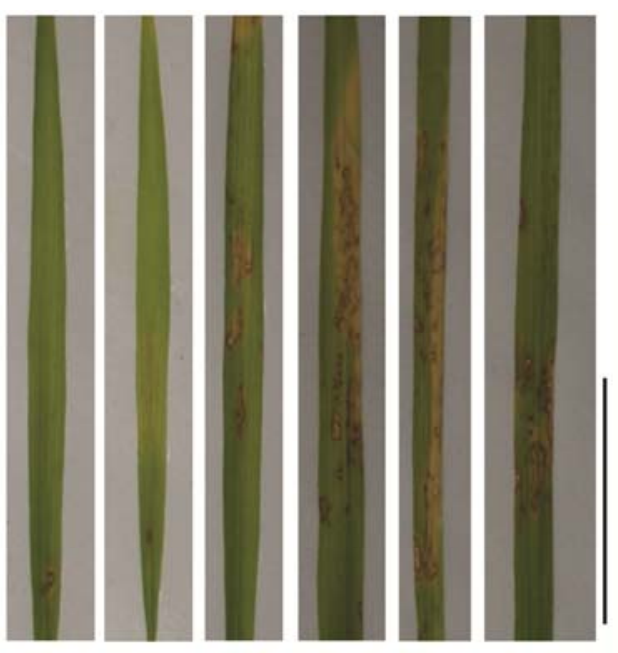

RI9 RI11 WT MT OV4 OV5

C

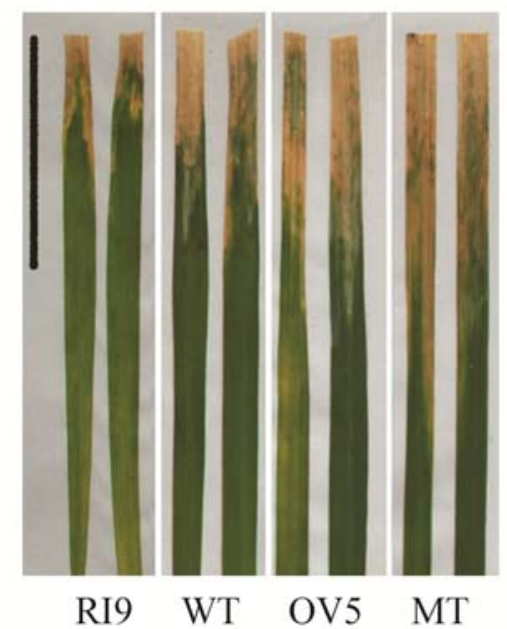

D

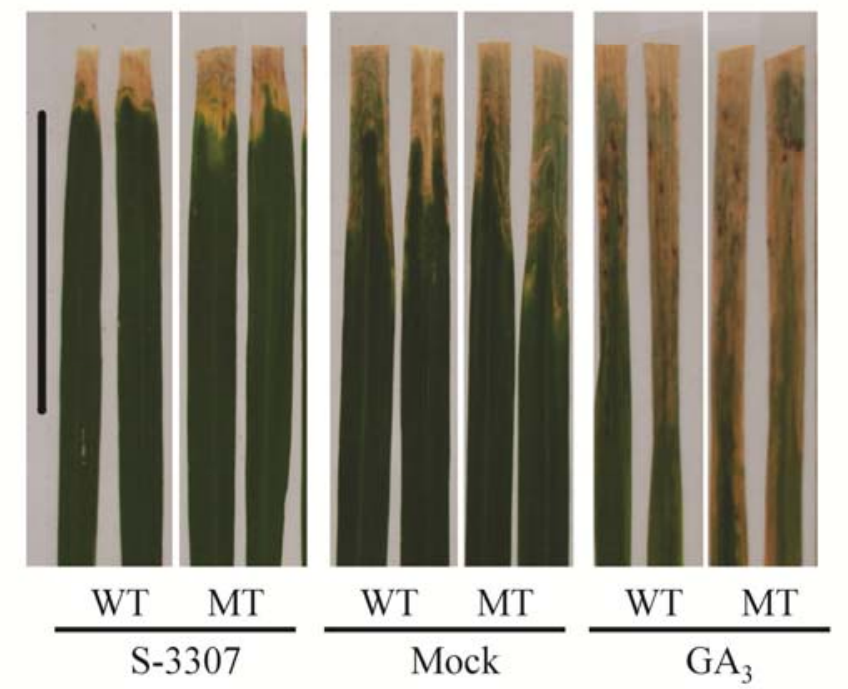

E

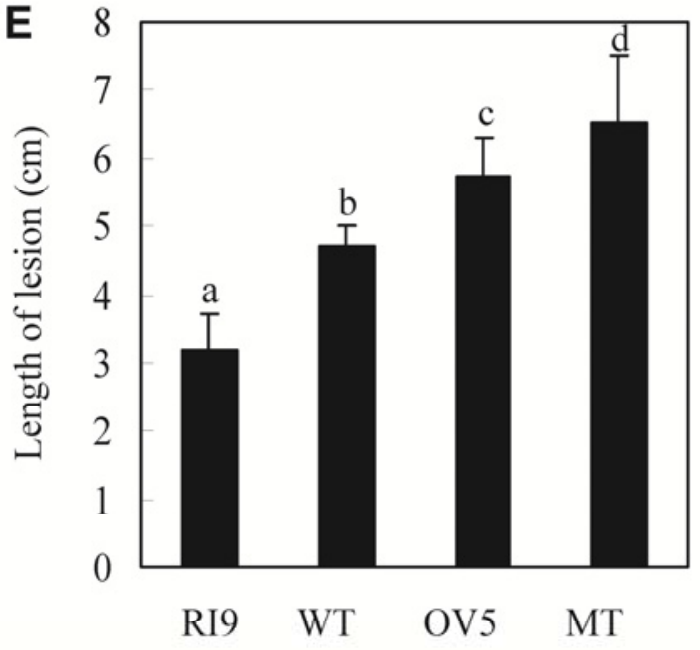

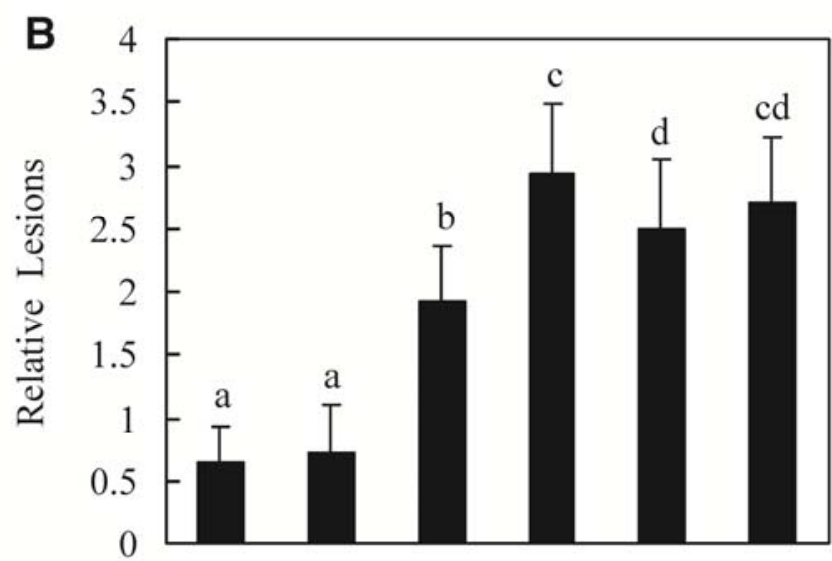

RI9 RI11 WT MT OV4 OV5

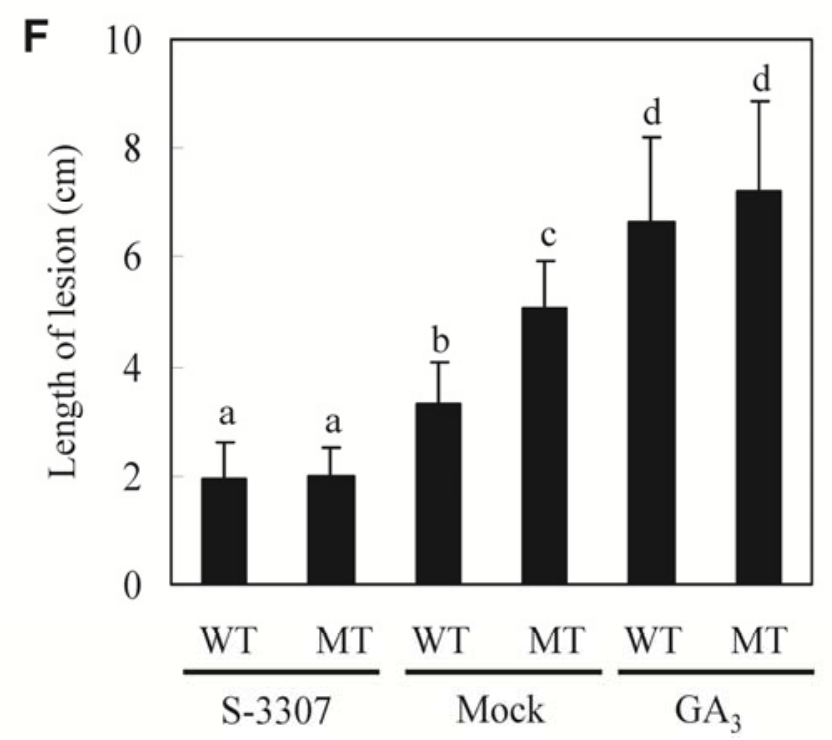

Fig. 6. OsGA20ox3 plays a negative role in rice resistance to Magnaporthe oryzae and Xanthomonas oryzae pv. oryzae. Three-week-old rice plants were inoculated with conidial suspensions $\left(2 \times 10^{5}\right)$ of $M$. oryzae MS220 by spray. A, Photos were taken at 7 days postinoculation (dpi). B, Disease index was evaluated by counting the number of lesions on the third leaves of the rice plants. Mean values and standard errors were from 8 plants. C, Plants (approximately 6 weeks old) were inoculated with $X$. oryzae pv. oryzae PXO99 by the leaf-clipping method and photos were taken at 12 dpi. D, Two-weekold seedlings were sprayed with $60 \mu \mathrm{M} \mathrm{GA}_{3}, 20 \mu \mathrm{M}$ GA synthetic inhibitor S-3307, or $0.1 \%$ ethanol as the control six times at an interval of 4 days each. Two days after the last spray, the plants were inoculated with $X$. oryzae pv. oryzae as described in $\mathbf{C}$. $\mathbf{E}$ and $\mathbf{F}$, Lesion length was measured and shown as mean values and standard errors from 10 plants. Bar $=5 \mathrm{~cm}$. 
pathogen than the WT. Conversely, the OsGA20ox3 RNAi lines RI9 and RI11 developed less disease than the WT plants (Fig. $6 \mathrm{~A}$ and $\mathrm{B})$.

We also inoculated these plants with the bacterial pathogen $X$. oryzae pv. oryzae race 6 (strain PXO99) using the leaf-clipping method. The disease lesions were longer in the $17 \mathrm{~S}-14$ mutant plants than those in the WT plants (Fig. 6C and E). In contrast, suppression of OsGA20ox3 expression in RNAi plants was correlated with less lesion development, whereas the overexpressing lines showed more severe disease than the WT plants. To further investigate the effect of GA on disease responses, the $17 \mathrm{~S}-14$ and WT plants were treated with $\mathrm{GA}_{3}$ or GA synthesis inhibitor S-3307. The lesion development was inhibited in both the WT and 17S-14 plants by S-3307 (Fig. $6 \mathrm{D}$ and $\mathrm{F}$ ). In contrast, the lesion symptom was enhanced by $\mathrm{GA}_{3}$ in both the WT and 17S-14 plants.

Next, we examined the expressions of genes related to defense reactions. We found that expression of pathogenesisrelated $(P R)$ genes $(O s P R I b$ and $O s P R 10[P B Z 1])$ was induced by inoculation of $M$. oryzae in all plants but the induction was lower in 17S-14 and OsGA20ox3-overexpression line OV4 and higher in the RNAi line RI9 compared with the WT plants (Fig. 7A and B). OsGA20ox3 and its close homologous OsGA20ox2 transcript level was not changed significantly in the WT or the RNAi line RI9 in response to infection by the rice blast fungus, and only slight variations of OsGA20ox3 expression were detected in 17S-14 and overexpressing plants in response to the pathogen treatment (Fig. 7C). Increase of OsWRKY71 expression has been reported to enhance disease resistance in rice (Liu et al. 2006). We found that both the basal and induced levels of the OsWRKY71 transcript were suppressed in 17S-14 and OsGA20ox3-overexpressing plants and increased slightly in the RNAi line RI9 in comparison with the WT (Fig. 7D). Finally, diterpene cyclases, ent-copalyl diphosphate (ent-CDP) synthase (OsCPS2/OsCyc2), and syn-CDP synthase (OsCPS4/OsCyc1) catalyze the production of precursors leading to synthesis of phytoalexins (Kanno et al. 2006). We found that the OsCPS2 and OsCPS4 transcript levels were higher in the OsGA20ox3 RNAi line RI9 than those of the WT, 17S-14, and OsGA20ox3overexpressing plants (Fig. 7E and F). Altogether, these results show that alterations in OsGA20ox3 expression affect the expression of defense response genes that have been shown to be associated with rice resistance to pathogens.

\section{DISCUSSION}

In this study, we aimed at transgenically expressing the $O s$ $W A K 2$ gene to assess the role of OsWAK2 in disease resistance, and we isolated a rice mutant, $17 \mathrm{~S}-14$, that showed a GA-constitutive response phenotype. However, by accident, the isolation of this mutant, caused by a partial T-DNA insertion carrying a truncated $O s W A K 2$, led us to discover that previously unknown role of OsGA20ox3 in GA biosynthesis. In addition, we found that the $17 \mathrm{~S}-14$ mutant was more susceptible to two major rice pathogens, the rice blast fungus $M$. oryzae and the rice blight bacterium $X$. oryzae pv. oryzae. Collectively, our results add to a growing body of evidence that GA plays a dual role in promoting growth and disease susceptibility in plants.

Gain-of-function mutations can be misleading but sometimes can also be an effective method for indicating gene func-
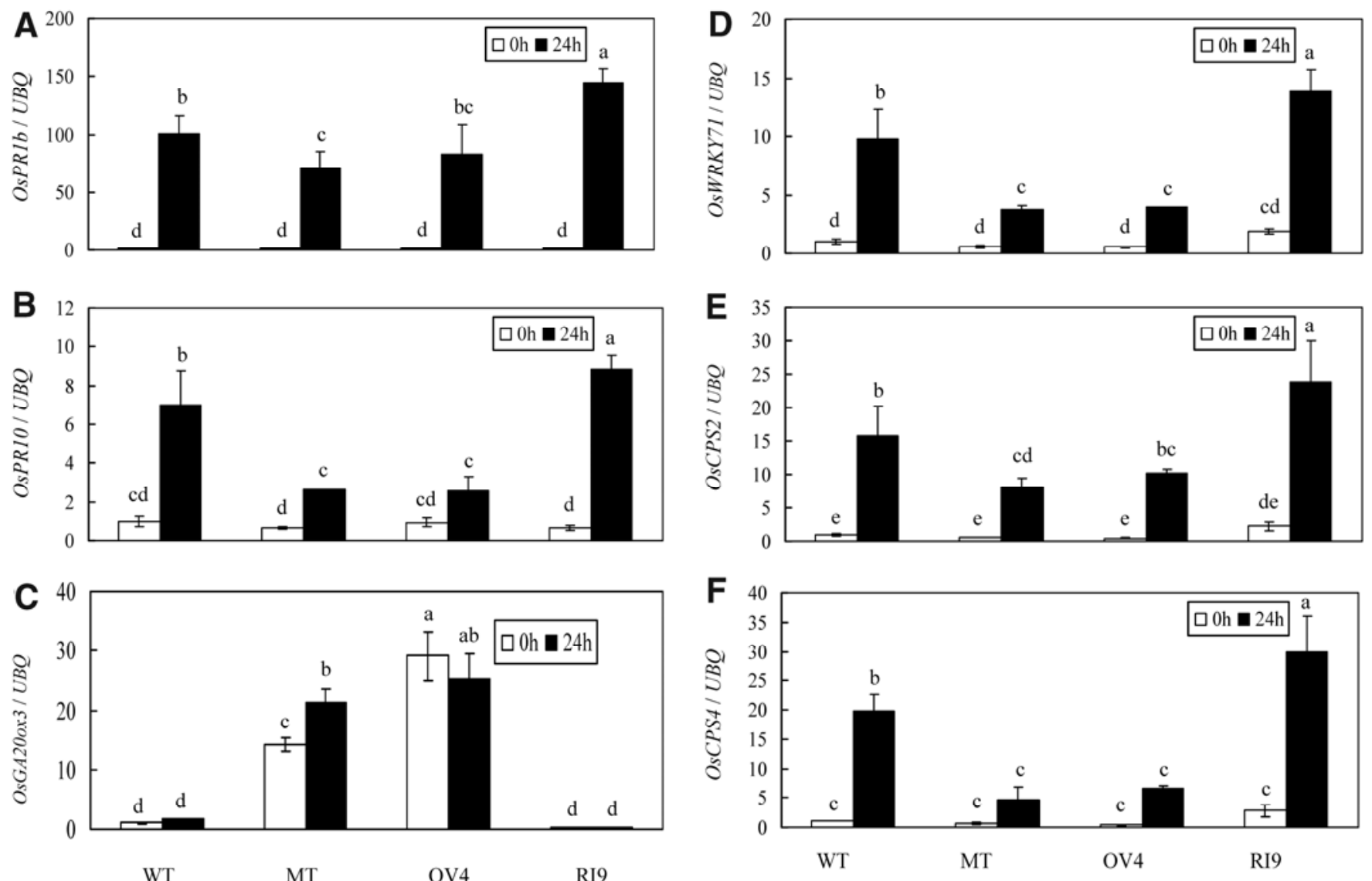

Fig. 7. OsGA20ox3 negatively regulates expression of defense-related genes Three-week-old rice plants were inoculated with Magnaporthe oryzae and sampled at the time points indicated. Samples collected at 0 and $24 \mathrm{~h}$ post-pathogen inoculation were used for quantitative polymerase chain reaction analysis of the expression of $\mathbf{A}, O s P R 1 b ; \mathbf{B}$, OsPR10; C, OsGA20ox3; D, OsWRKY71; E, OsCPS2; andF, CPS4. The ubiquitin (UBQ) gene was used as internal standard. Mean values and standard errors from three repeats are shown. 
tion, especially for genes that are members of a multi-gene family with redundant functions (Nakamura et al. 2007). Our analysis of the $17 \mathrm{~S}-14$ mutant illustrates the utility of a gainof-function mutation in the elucidation of the OsGA20ox3 function in GA biosynthesis. The enhanced expression of the OsGA20ox3 transcript, due to insertion of CaMV35S promoter-carrying T-DNA upstream of this gene, was the first indication that the constitutive GA response phenotype in the $17 \mathrm{~S}-14$ mutant might be caused by overexrpession of OsGA20ox3, which belongs to a four-member gene family. We were able to confirm the causal effect of OsGA20ox3 overexpression in the $17 \mathrm{~S}-14$ mutant by independently producing and characterizing OsGA20ox3-overexpressing and RNAi-silenced transgenic rice plants. Our studies demonstrate that OsGA20ox3 plays a role similar to that of its homologous OsGA20ox1 and SD1 (OsGA20ox2) gene in GA biosynthesis and regulating plant growth.

In many cases, the sites where bioactive GA are produced associate with the sites of their action (Kaneko et al. 2003; Yamaguchi 2008). In this study, expression of OsGA20ox3 was observed in leaves, sheaths, and roots of 2-week-old seedlings but not in these tissues at the heading stage of rice (Fig. 4A), suggesting that OsGA20ox3 participates in the process of active growth in young plants. GUS activity staining also showed OsGA20ox3 specifically expressed in growing tissues and in young panicles, anthers, and pollens (Fig. 4B). Bioactive GA are accumulated at a high level in the anthers of many plants (Hasegawa et al. 1995) and considered to be a source for other floral organs (Kaneko et al. 2003; Weiss et al. 1995). Previous studies have shown that OsGA20oxl and OsGA3oxl are expressed specifically in the tapetum of the anther and the epithelium of the embryo, suggesting the role of these genes in preferential production of $\mathrm{GA}_{4}$ that functions as a paracrine for other tissues and organs, whereas OsGA20ox2 and OsGA3ox2 are considered to be another set of enzymes that preferentially produce $\mathrm{GA}_{1}$ during the vegetative and reproductive stages (Kaneko et al. 2003). The expression profile of OsGA20ox3 suggests that OsGA20ox3 can complement the function of OsGA20ox1 and OsGA20ox2 in GA biosynthesis, supported by increased accumulation of both $\mathrm{GA}_{1}$ and $\mathrm{GA}_{4}$ in the $17 \mathrm{~S}-14$ mutant (Table 1). GA play important roles in regulating flowering and development of floral organs (Aya et al. 2009; Chhun et al. 2007). The GA-deficient mutant of rice causes impaired pollen germination and pollen growth. We also noticed that the OsGA20ox3 RNAi lines of semidwarf plants set much fewer seeds than the WT plants (data not shown). The results demonstrated that gene OsGA20ox3 plays positive roles in growth and reproduction, similar to OsGA20oxl and OsGA20ox2.

Emerging evidence suggests that GA are involved not only in plant development but also in disease resistance. In fact, GA were first isolated from the fungal pathogen $G$. fujikuroi (Yabuta and Sumiki 1938), which causes super-elongated rice. The rice eui mutant, which hyperaccumulates active Gas, displays compromised disease resistance to $X$. oryzae pv. oryzae and $M$. oryzae (Yang et al. 2008), suggesting that GA acts in pathogenicity. Conversely, the GA perception-deficient mutant gidl shows enhanced resistance to $M$. oryzae (Tanaka et al. 2006). In Arabidopsis, the mutant with loss-of-function in DELLA proteins which exhibits constitutive activation of GA signaling, is more resistant to biotrophic bacterial pathogens but hyper-susceptible to necrotrophic pathogens (Navarro et al. 2008; Robert-Seilaniantz et al. 2007). In this study, we found that the $17 \mathrm{~S}-14$ mutant is more susceptible to bacterial blight and rice blast than the WT plants (Fig. 6A and C). Furthermore, suppression of GA synthesis by a GA biosynthetic inhibitor increased resistance to $X$. oryzae pv. oryzae. In contrast, exoge- nous $\mathrm{GA}_{3}$ treatment made plants more susceptible to $X$. oryzae pv. oryzae (Fig. 6C). These results not only are consistent with the notion that GA potentially can be effective virulence factors for certain plant pathogens, such as G. fujikuroi, but also suggest that a high level accumulation of GA during certain stages of normal plant development or under certain environmental conditions that promote rapid plant growth may be accompanied by heighted disease susceptibility. As such, GA-mediated growth-defense conflict likely has significant practical implications in agriculture.

A number of observations indicate that crosstalks between phytohormones are important for coordinating growth and development with adaptation to environmental stresses. Auxin promotes the accumulation of bioactive GA (Frigerio et al. 2006), whereas GA is required for proper auxin transport (Willige et al. 2011). Suppression of auxin signaling is thought to be part of the salicylic acid (SA)-mediated plant defense mechanism in Arabidopsis (Wang et al. 2007). The SA-mediated growth inhibition may be associated with alternation of GA signaling and responsiveness (Gallego-Giraldo et al. 2011) as well as auxin signaling (Wang et al. 2007). A negative crosstalk between GA signaling and jasmonate signaling has also be reported (Yang et al. 2012). Brassinosteroid (BR) receptor (BRI1)-associated kinase can cooperate with BRI1 for plant growth and with the receptors of microbial-associated molecular patterns for plant immunity. It has been demonstrated that BR-mediated growth antagonizes innate immune response in Arabidopsis (Albrecht et al. 2012; Belkhadir et al. 2012). BR acts as a virulent factor to suppress defense mechanism against rice root oomycete Pythium graminicola, at least in part, through negative crosstalk with SA and GA pathways (De Vleesschauwer et al. 2012). Interestingly, the expression of OsGA20ox3 is inhibited by $P$. graminicola inoculation, whereas $O s G A 2 o x 3$, the GA-degrading enzyme gene, is induced by $P$. graminicola infection. It was shown that BR, in this case, antagonizes GA-mediated defenses by interfering with GA metabolism, leading to enhanced stabilization of SLR1, the only DELLA protein in rice (De Vleesschauwer et al. 2012). These data highlight the central importance of phytohormone homeostasis in balancing growth and immunity in plants, and our results provide new insights into this balance by demonstrating an important role of OsGA20ox3 in regulating rice growth and defense.

\section{MATERIALS AND METHODS}

\section{Plant growth conditions.}

For germination, seeds of the 17S-14 mutant and its WT progenitor (Oryza sativa L. japonica, Aichi Asahi) were sterilized and rinsed with sterile water, then imbibed in water at $37^{\circ} \mathrm{C}$ for 1 day. The germinated seed were transferred to the mixture of peat/vermiculite $(3: 1, \mathrm{vol} / \mathrm{vol})$ and grown in a greenhouse at ambient temperature (approximately $28^{\circ} \mathrm{C}$ ) under natural sunlight.

\section{Chemical treatments.}

Seeds of the 17S-14 mutant and WT were sterilized in water and were germinated at $37^{\circ} \mathrm{C}$. The seed-emerged buds were placed on the one-half Murashige-Skoog solid media containing various amounts of $\mathrm{S}-3307$ or $\mathrm{GA}_{3}$ and grown at $28^{\circ} \mathrm{C}$ under fluorescent light (14 h of light and $10 \mathrm{~h}$ of darkness). The second leaf sheath lengths of seedlings were measured 10 days after treatments, and six plants were evaluated for each treatment.

To examine the effects of GA and its inhibitor on disease resistance, 2-week-old seedlings were sprayed with $20 \mu \mathrm{M}$ S-3307, $60 \mu \mathrm{M} \mathrm{GA}_{3}$, or $0.1 \%$ ethanol as the control, six times, at an interval of 4 days. Two days after the last application, seedlings were inoculated with $X$. oryzae pv. oryzae. 
Construction and screening of a rice subgenomic library.

Genomic DNA of the 17S-14 mutant was digested with EcoRI and separated in a $0.8 \%$ (wt/vol) low-melting agarose gel. According to the result from parallel Southern blot analysis using another gel, a segment of the gel corresponding to the position of Hyg ( Hyg) phosphotransferase probes was excised out. The DNA purified from the gel was ligated to pBluescript SK II vector. Individual transformants were inoculated into wells of a 384-well microplate and grown in Luria-Bertani medium at $37^{\circ} \mathrm{C}$ overnight. The bacteria were transferred onto a nylon membrane (Hybond-N ${ }^{+}$; Amersham Pharmacia Biotech, Buckinghamshire, U.K.) and used for screening clones harboring the $H y g$ gene. In total, approximately $2 \times 10^{5}$ clones were screened. DNA labeling and Southern blotting were performed as described by Sakamoto and associates (2001).

\section{Generation of transgenic plants.}

The full-length coding sequence of $O s G A 200 \times 3$ was isolated by PCR using forward primer OX3gKpnF: $5^{\prime}$-attggtacctgatcag ccatggcagccg- $3^{\prime}$ and reverse primer OX3gBamHR: $5^{\prime}$-cttggatc ctcccatctgtctagtacttgtcg- $3^{\prime}$. The PCR product was digested with KpnI and BamHI and inserted into the same sites behind the CaMV35S promoter in a modified pCambia1301 vector.

For making RNAi constructs, fragments of OsGA20ox3 were amplified by PCR using two forward primers OX3KpnF: $5^{\prime}$-tttggtaccgttgtgtttacatgcagggaggtgt- $3^{\prime}$ and OX3HXbaF: $5^{\prime}$-aa taagcttctctagatgtaccaggagtactgcg- $3^{\prime}$ and paired respectively with a reverse primer OX3SalR: 5'-aaagtcgacccagcgtcaggtgcgg-3'. The fragments were constructed to generate self-complementary hairpin RNA after enzyme digestions and ligations. The hairpin structure was placed under the control of the CaMV35S promoter.

For making the promoter-GUS fusion construct, the OsGA20ox3 promoter region of approximately 1,500 bp was obtained by PCR using primers of OX3pF: $5^{\prime}$-tttaagcttgctcgcg gtttactgacggattctat- $3^{\prime}$ and $\mathrm{OX} 3 \mathrm{pR}$ : $5^{\prime}$-ttccccgggatcgaacaccacgg ctgccat- $3^{\prime}$. The promoter fragment was inserted in frame with the $G U S$ gene into a modified pCambia1301 vector to generate

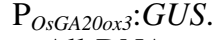

All DNA constructs were introduced into rice calli of Aichi Asahi by Agrobacterium-mediated transformation. Overexpression and RNAi lines in the $\mathrm{T}_{2}$ generation and promoter lines in the $T_{1}$ generation were screened by planting seeds on one-half Murashige-Skoog medium (containing 0.6\% agar) supplemented with Hyg at $30 \mu \mathrm{g} / \mathrm{liter}$, and antibiotic-resistant seedlings were used for experiments.

\section{RT-PCR and real-time PCR.}

DNase-treated total RNA samples were reverse transcribed and the cDNA products were used for PCR amplifications. The primers were shown in Supplementary Table S1 and an OsActin gene was used as an internal standard for RT-PCR analysis. The PCR products were separated by electrophoresis on a $1.2 \%$ (wt/vol) agarose gel, and the DNA bands were visualized using the Alphaimager 2200 system (Alpha Innotech Corporation, San Leandro, CA, U.S.A.). Real-time quantitative PCR was performed using approximately $10 \mathrm{ng}$ of cDNA and SYBR Green PCR MasterMix (Takara Biotech, Dalian, China) in a $15-\mu l$ reaction volume using a StepOne Quantitative PCR system (Applied Biosystems, Foster, City, CA, U.S.A.) following the manufacturer's protocols.

\section{Quantitative analysis of $\mathrm{GA}_{1}$ and $\mathrm{GA}_{4}$.}

Endogenous GA extract and quantitative analysis were performed as described previously (Hirano et al. 2008; Oikawa et al. 2004; Zhu et al. 2006). One-week-old seedlings of mutant $17 \mathrm{~S}-14$ and WT were harvested and ground to powder in liquid nitrogen. The powders (approximately $20 \mathrm{~g}$ ) were extracted with $300 \mathrm{ml}$ of pre-cooled aqueous methanol $(80 \% \mathrm{MeOH}$ [vol/vol]) for $6 \mathrm{~h}$ at $4^{\circ} \mathrm{C}$. The extract was collected by filtration through a filter paper. The residue and filter paper were re-extracted with $200 \mathrm{ml}$ of $80 \% \mathrm{MeOH}$. The combined filtrates were added with $10 \mathrm{ng}$ of deuterated $\left[17.17-{ }^{2} \mathrm{H}_{2}\right] \mathrm{GA}_{1}$ and $100 \mathrm{ng}$ of [17.17${ }^{2} \mathrm{H}_{2} \mathrm{GA}_{4}$ (purchased from Australian National University) as internal standards and concentrated to approximately $40 \mathrm{ml}$ under vacuum below $35^{\circ} \mathrm{C}$. The aqueous solution left was adjusted to $\mathrm{pH} 3.0$ with $6 \mathrm{M} \mathrm{HCl}$ and then extracted with ethyl acetate (EtOAc, $50 \mathrm{ml}$, three times). The combined EtOAc was dried by $\mathrm{Na}_{2} \mathrm{SO}_{4}$ and filtered. The filtrate was concentrated to dryness and redissolved in $5 \mathrm{ml}$ of $\mathrm{MeOH}$. The solution was prepurified in a preparative high-performance liquid chromatography system using an ODS-AP SP-120-15, 250-by-10-mm column (Japan Analytical Industry Co., Ltd., Japan). The fractions collected (60\% MeOH containing $1 \%$ acetic acid) were evaporated by a stream of nitrogen gas and the residue was resuspended in $100 \mu \mathrm{l}$ of $\mathrm{MeOH}$. The active $\mathrm{GA}\left(\mathrm{GA}_{1}\right.$ and $\left.\mathrm{GA}_{4}\right)$ in the solutions were detected by an LC-MS system (Agilent [Santa Clara, CA, U.S.A.] 1100 Liquid Chromatography with a Phenonenex Luna $3 \mu \mathrm{m} \mathrm{C18,} \mathrm{150-by-2-mm} \mathrm{column;} \mathrm{Bruker}$ Esquire 6000 mass spectrograph [Billerica, MA, U.S.A.]). The mobile phase was $\mathrm{MeOH}$ (containing $0.1 \%$ formic acid) with a linear gradient from 30 to $100 \%$. The linear gradient elution program for $\mathrm{GA}_{1}$ was as follows: $30 \% \mathrm{MeOH}$ for $5 \mathrm{~min}$, from 30 to $70 \% \mathrm{MeOH}$ in $20 \mathrm{~min}$, from 70 to $100 \% \mathrm{MeOH}$ in $5 \mathrm{~min}$, and column washing for $10 \mathrm{~min}$. The linear gradient elution program for $\mathrm{GA}_{4}$ was as follows: $40 \% \mathrm{MeOH}$ for $5 \mathrm{~min}$, from 40 to $100 \% \mathrm{MeOH}$ in $30 \mathrm{~min}$, and $100 \% \mathrm{MeOH}$ for $10 \mathrm{~min}$. The retention times of $\mathrm{GA}_{1}$ and $\mathrm{GA}_{4}$ were approximately 15.8 and 27.3 $\mathrm{min}$, respectively. The characteristic ions were monitored as follows: $329,303,285,241,259,301$, and 273 for $\mathrm{GA}_{1} ; 331,305$, $287,243,261,303$, and 275 for $\left[17.17-{ }^{2} \mathrm{H}_{2}\right] \mathrm{GA}_{1} ; 313,287,243$, 269, 225, 285, and 257 for $\mathrm{GA}_{4}$; and 315, 289, 245, 271, 227, 287, and 259 for $\left[17.17-{ }^{2} \mathrm{H}_{2}\right] \mathrm{GA}_{4}$. The quantity of $\mathrm{GA}_{1}$ and $\mathrm{GA}_{4}$ in the original extracts was calculated by the abundance ratio of characteristic ion pairs: $329 / 331$ for $\mathrm{GA}_{1}$ and $\left[17.17-{ }^{2} \mathrm{H}_{2}\right] \mathrm{GA}_{1}$, and $313 / 315$ for $\mathrm{GA}_{4}$ and $\left[17.17-{ }^{2} \mathrm{H}_{2}\right] \mathrm{GA}_{4}$, respectively. The other ions were monitored to confirm the identification of the compounds analyzed.

\section{Histochemical GUS staining.}

Various organs of transgenic lines of the $T_{1}$ generation were prepared for histochemical GUS staining, and WT plants (Aichi Asahi) were used as controls. Samples were incubated in GUS staining buffer $(50 \mathrm{mM}$ sodium phosphate [pH 7.0], $10 \mathrm{mM}$ EDTA-Na, $20 \%$ methanol, $0.1 \%$ Triton X-100, and X-Gluc at $0.5 \mathrm{mg} / \mathrm{ml}$ ) at $37^{\circ} \mathrm{C}$ for $3 \mathrm{~h}$, after vacuum infiltration for $5 \mathrm{~min}$. Chlorophyll was cleared from the plant tissues by immersing the samples in $70 \%$ ethanol. Three independent experiments were performed and more than $10 \mathrm{P}_{O_{s G A 20 o x 3}}$ GUS transgenic plants were observed.

\section{Pathogen growth and inoculation.}

Inoculation of rice plants with $M$. oryzae was conducted in a controlled growth chamber as described by Peng and Shishiyama (1988). To examine disease resistance, the virulent strain MS220 was used. Spores were harvested and suspended. Three-week-old plants were inoculated with spore suspensions of $M$. oryzae at $2 \times 10^{5}$ conidia $/ \mathrm{ml}$ (containing $0.01 \%$ silwet) by spray. The plants treated were kept in darkness for $48 \mathrm{~h}$ at $28^{\circ} \mathrm{C}$ and then in a greenhouse under natural sunlight with $95 \%$ humidity. After 7 days, the number of lesions was counted on the third leaves of the rice plants and at least eight leaves were evaluated. Leaves of some of these plants were also analyzed for gene expression. 
$X$. oryzae pv. oryzae race 6 (strain PX099) was grown in potato dextrose agar medium at $28^{\circ} \mathrm{C}$ for 3 days and collected by centrifugation. The bacteria were suspended in $10 \mathrm{mM} \mathrm{MgCl}$ at a concentration of $10^{8} \mathrm{CFU} / \mathrm{ml}$ for inoculation. Six-weekold plants of the 17S-14 mutant, WT, and transgenics were inoculated with PXO99 using the leaf-clipping method and grown under natural sunlight in a greenhouse at approximately $28^{\circ} \mathrm{C}$. Lesion length was recorded at 12 days post inoculation.

\section{ACKNOWLEDGMENTS}

This work was supported by the State Basic Research and Development Plan (2012CB114006), the Natural Science Foundation of China (31171833 and 30900927), and the Program for Changjiang Scholars and Innovative Research Team in University (IRT042). We thank Professors Sheng Yang He (Michigan State University) and Jun Fan (China Agricultural University) for critical reading of the manuscript.

\section{LITERATURE CITED}

Albrecht, C., Boutrot, F., Segonzac, C., Schwessinger, B., GimenezIbanez, S., Chinchilla, D., Rathjen, J. P., de Vries, S. C., and Zipfel, C. 2012. Brassinosteroids inhibit pathogen-associated molecular patterntriggered immune signaling independent of the receptor kinase BAK1. Proc. Natl. Acad. Sci. U.S.A. 109:303-308.

Aya, K., Ueguchi-Tanaka, M., Kondo, M., Hamada, K., Yano, K., Nishimura M., and Matsuoka, M. 2009. Gibberellin modulates anther development in rice via the transcriptional regulation of GAMYB. Plant Cell 21:14531472

Belkhadir, Y., Jaillais, Y., Epple, P., Balsemão-Pires, E., Dangl, J. L., and Chory, J. 2012. Brassinosteroids modulate the efficiency of plant immune responses to microbe-associated molecular patterns. Proc. Natl. Acad. Sci. U.S.A. 109:297-302.

Chhun, T., Aya, K., Asano, K., Yamamoto, E., Morinaka, Y., Watanabe, M., Kitano, H., Ashikari, M., Matsuoka, M., and Ueguchi-Tanaka, M. 2007. Gibberellin regulates pollen viability and pollen tube growth in rice. Plant Cell 19:3876-3888.

De Vleesschauwer, D., Van Buyten, E., Satoh, K., Balidion, J., Mauleon, R., Choi, I.-R., Vera-Cruz, C., Kikuchi, S., and Höfte M. 2012. Brassinosteroids antagonize gibberellin- and salicylate-mediated root immunity in rice. Plant Physiol. 158:1833-1846.

Frigerio, M., Alabadí, D., Pérez-Gómez, J., García-Cárcel, L., Phillips, A. L., Hedden, P., and Blázquez, M. A., 2006. Transcriptional regulation of gibberellin metabolism genes by auxin signaling in Arabidopsis. Plant Physiol. 142:553-563.

Gallego-Giraldo, L., Escamilla-Trevino, L., Jackson, L. A., and Dixon, R. A. 2011. Salicylic acid mediates the reduced growth of lignin downregulated plants. Proc. Natl. Acad. Sci. U.S.A. 108:20814-20819.

Hasegawa, M., Nakajima, M., Takeda, K., Yamaguchi, I., Murofushi, N. 1995. Endogenous levels of gibberellins in normal and male-sterile anthers of rice (Oryza sativa cv. Nihonmasari). Biosci. Biotechnol. Biochem. 59:1716-1720.

Hedden, P., and Phillips, A. L. 2000. Gibberellin metabolism: New insights revealed by the genes. Trends Plant Sci. 5:523-530.

Hedden, P., Phillips, A. L., Rojas, M. C., Carrera, E., and Tudzynski, B. 2002. Gibberellin biosynthesis in plant and fungi: A case of convergent evolution? J. Plant Growth Regul. 20:319-331.

Hirano, K., Aya, K., Hobo, T., Sakakibara, H., Kojima, M., Rosalyn, A. S., Hasegawa, Y., Ueguchi-Tanaka, M., and Matsuoka, M. 2008. Comprehensive transcriptome analysis of phytohormone biosynthesis and signaling genes in microspore/pollen and tapetum of rice. Plant Cell Physiol. 49:1429-1450.

Ikeda, A., Ueguchi-Tanaka, M., Sonoda, Y., Kitano, H., Koshioka, M., Futsuhara, Y., Matsuoka, M., and Yamaguchi, J. 2001. Slender rice, a constitutive gibberellin response mutant, is caused by a null mutation of the SLR1 gene, an ortholog of the height-regulating gene GAI/RGA/ RHT/D8. Plant Cell 13:999-101.

Kaneko, M., Itoh, H., Inukai, Y., Sakamoto, T., Ueguchi-Tanaka, M., Ashikari, M., and Matsuoka, M. 2003. Where do gibberellin biosynthesis and gibberellin signaling occur in rice plants? Plant J. 35:104115 .

Kanno, Y., Otomo, K., Kenmoku, H., Mitsuhashi, W., Yamane, H., Oikawa, H., Toshima, H., Matsuoka, M., Sassa, T., and Toyomasu, T. 2006. Characterization of a rice gene family encoding type-A diterpene cyclases. Biosci. Biotechnol. Biochem. 70:1702-1710.

Li, H., Zhou, S. Y., Zhao, W. S., Su, S. C., and Peng, Y. L. 2009. A novel wall-associated receptor-like protein kinase gene, OsWAK1, plays important roles in rice blast disease resistance. Plant Mol. Biol. 69:337346.

Liu, X. Q., Bai, X. Q., Wang, X. J., and Chu, C. C. 2006. OsWRKY71, a rice transcription factor, is involved in rice defense response. J. Plant Physiol. 164:969-979.

Liu, Y.-G., Mitsukawa, N., Oosumi, T., and Whittier. R. F. 1995. Efficient isolation and mapping of Arabidopsis thaliana T-DNA insert junctions by thermal asymmetric interlaced PCR. Plant J. 8:457-463.

MacMillan, J. 2002. Occurrence of gibberellin in vascular plants, fungi and bacteria. J. Plant Growth Regul. 20:387-442.

Nakamura, H., Hakata, M., Amano, K., Miyao, A., Toki, N., Kajikawa, M., Pang, J., Higashi, N., Ando, S., Toki, S., Fujita, M., Enju, A., Seki, M., Nakazawa, M., Ichikawa, T., Shinozaki, K., Matsui, M., Nagamura, Y., Hirochika, H., and Ichikawa, H. 2007. A genome-wide gain-of-function analysis of rice genes using the FOX-hunting system. Plant Mol. Biol. 65:357-371.

Navarro, L., Bari, R., Achard, P., Lisón, P., Nemri, A., Harberd, N. P., and Jones, J. D. 2008. DELLAs control plant immune responses by modulating the balance of jasmonic acid and salicylic acid signaling. Curr. Biol. 18:650-655.

Oikawa, T., Koshioka, M., Kojima, K., Yoshida, H., and Kawata, M. 2004. A role of OsGA20ox1, encoding an isoform of gibberellin 20oxidase, for regulation of plant stature in rice. Plant Mol. Biol. 55:687700 .

Olszewski, N., Sun, T. P., and Gubler, F. 2002. Gibberellin signaling: Biosynthesis, catabolism, and response pathways. Plant Cell 14:61-80.

Otomo, K., Kenmoku, H., Oikawa, H., König, W. A., Toshima, H., Mitsuhashi, W., Yamane, H., Sassa, T., and Toyomasu, T. 2004. Biological functions of ent- and syn- copalyl diphosphate synthases in rice: Key enzymes for the branch point of gibberellin and phytoalexin biosynthesis. Plant J. 39:886-893.

Peng, Y. L., and Shishiyama, J. 1988. Temporal sequence of cytological events in rice leaves affected with Pyricularia oryzae. Can. J. Bot. 66:730-735.

Prisic, S., Xu, M. M., Wilderman, R., and Peters, R. J., 2004. Rice contains two disparate ent-copalyl diphosphate syntheses with distinct metabolic functions. Plant Physiol. 136:4228-4236.

Qiao, F., Yang, Q., Wang, C. L., Fan, Y. L., Wu, X. F., and Zhao, K. J. 2007. Modification of plant height via RNAi suppression of OsGA20ox2 gene in rice. Euphytica 158:35-45.

Rieu, I., Ruiz-Rivero, O., Fernandez-Garcia, N., Griffiths, J., Powers, S. J., Gong, F., Linhartova, T., Eriksson, S., Nilsson, O., Thomas, S. G., Phillips, A. L., and Hedden, P. 2008. The gibberellin biosynthetic genes AtGA20ox1 and AtGA20ox2 act, partially redundantly, to promote growth and development throughout the Arabidopsis life cycle. Plant J. 53:488-504.

Robert-Seilaniantz, A., Navarro, L., Bari, R., and Jones, J. D. G. 2007. Pathological hormone imbalances. Curr. Opin. Plant Biol. 10:372-379.

Sakamoto, T., Kobayashi, M., Itoh, H., Tagiri, A., Kayano, T., Tanaka, H., Iwahori, S., and Matsuoka, M. 2001. Expression of a gibberellin 2-oxidase gene around the shoot apex is related to phase transition in rice. Plant Physiol. 125:1508-1516.

Sakamoto, T., Miura, K., Itoh, H., Tatsumi, T., Ueguchi-Tanaka, M., Ishiyama, K., Kobayashi, M., Agrawal, G. K., Takeda, S., Abe, K., Miyao, A., Hirochika, H., Kitano, H., Ashikari, M., and Matsuoka, M. 2004. An overview of gibberellin metabolism enzyme genes and their related mutants in rice. Plant Physiol. 134:1642-1653.

Silverstone, A. L., and Sun, T. P. 2000. Gibberellins and green revolution. Trends Plant Sci. 5:1-2.

Tanaka, N., Matsuoka, M., Kitano, H., Asano, T., Kaku, H., and Komatsu, S. 2006. gid1, a gibberellin-insensitive dwarf mutant, shows altered regulation of probenazole-inducible protein (PBZ1) in response to cold stress and pathogen attack. Plant Cell Environ. 29:619-631.

Ueguchi-Tanaka, M., Ashikari, M., Nakajima, M., Itoh, H., Katoh, E., Kobayashi, M., Chow, T. Y., Hsing, Y. I. C., Kitano, H., Yamaguchi, I., and Matsuoka, M. 2005. GIBBERELLIN INSENSITIVE DWARF1 encodes a soluble receptor for gibberellin. Nature 437:693-698.

Ueguchi-Tanaka, M., Nakajima, M., Motoyuki, A., and Matsuoka, M. 2007. Gibberellin receptor and its role in gibberellin signaling in plants. Annu. Rev Plant Biol. 58:183-198.

Wang, D., Pajerowska-Mukhtar, K., Culler, A. H., and Dong, X. 2007. Salicylic acid inhibits pathogen growth in plants through repression of the auxin signaling pathway. Curr. Biol. 17:1784-1790.

Weiss, D., van der Luit, A., Knegt, E., Vermeer, E., Mol, J. N. M., and Kooter, J. M. 1995. Identification of endogenous gibberellins in petunia flowers. Plant Physiol. 107:695-702.

Willige, B. C., Isono, E., Richter, R., Zourelidou, M., and Schwechheimer, C. 2011. Gibberellin regulates PIN-FORMED abundance and is required for auxin transport-dependent growth and development in Arabidopsis thaliana. Plant Cell 23:2184-2195. 
Wolfgang, S., Ellis, M. H., and Chandler, P. M. 2002. Semidwarf (sd-1), "green revolution" rice, contains a defective gibberellin 20-oxidase gene. Proc. Natl. Acad. Sci. U.S.A. 99:9043-9048.

Yabuta, T., and Sumiki, Y. 1938. On the crystal of gibberellin, a substance to promote plant growth. J. Agric. Chem. Soc. Jpn. 14:1526.

Yamaguchi, S. 2008. Gibberellin metabolism and its regulation. Annu. Rev. Plant Biol. 59:225-251.

Yang, D.-L., Li, Q., Deng, Y. W., Lou, Y. G., Wang, M. Y., Zhou, G. X., Zhang, Y. Y., and He, Z. H. 2008. Altered disease development in the eui mutants and eui overexpressors indicates that gibberellins negatively regulate rice basal disease resistance. Mol. Plant 13:1-10.
Yang, D.-L., Yao, J., Mei, C.-S., Tong, X.-H., Zeng, L.-J., Li, Q., Xiao, L.-T. Sun, T.-p., Li, J., Deng, X.-W., Lee, C. M., Thomashow, M. F., Yang, Y., He, Z., and He, S. Y. 2012. Plant hormone jasmonate prioritizes defense over growth by interfering with gibberellin signaling cascade. Proc. Natl. Acad. Sci. U.S.A. 109:1192-1200.

Zhu, Y. Y., Nomura, T., Xu, Y. H., Zhang, Y. Y., Peng, Y., Mao, B. Z. Hanada, A., Zhou, H. C., Wang, R. X., Li, P. J., Zhu, X. D., Mander, W. N., Kamiya, Y., Yamaguchi, S., and He, Z. H. 2006. ELONGATED UPPERMOST INTERNODE encodes a cytochrome P450 monooxygenase that epoxidizes gibberellins in a novel deactivation reaction in rice. Plant Cell 18:442-456. 